\title{
Uterine blood flow of cows during the oestrous cycle and early pregnancy: effect of the conceptus on the uterine blood supply
}

\author{
S. P. Ford, J. R. Chenault and S. E. Echternkamp \\ U.S. Meat Animal Research Center, Federal Research, Science and Education Administration, \\ U.S. Department of Agriculture, Clay Center, Nebraska 68933, U.S.A.
}

\begin{abstract}
Summary. Blood flow to each uterine horn of cows during the oestrous cycle and early pregnancy was determined daily by use of electromagnetic blood flow probes placed around both middle uterine arteries. The pattern of blood flow to uteri of pregnant and non-pregnant cows was similar until Day 14 after mating or oestrus. Between Days 14 and 18 of pregnancy blood flow to the uterine horn containing the conceptus increased $(P<0.01) 2$ - to 3 -fold, whereas blood flow to the non-gravid uterine horn in these cows remained constant. No corresponding increase in blood flow to the uterine horn ipsilateral to the ovary bearing the CL was observed in nonpregnant cows during this 4-day period. By Day 19 of pregnancy, blood flow to the gravid uterine horn had returned to a level similar to that observed on Day 13. Blood flow to both uterine horns of pregnant cows remained constant from Days 19 to 25 and then increased to the gravid horn $(P<0.01)$ markedly until Day 30 whereas blood flow to the non-gravid horn remained low. Uterine blood flow during the oestrous cycle of non-pregnant cows was positively correlated $(P<0.01)$ with systemic concentrations of oestradiol and the ratio of oestradiol $(\mathrm{pg} / \mathrm{ml})$ to progesterone $(\mathrm{ng} / \mathrm{ml})$. There was no association between oestradiol concentrations and blood flow to the gravid uterine horn. These data indicate local control of uterine blood flow by the bovine conceptus which may function to create optimal conditions for the continuation of pregnancy.
\end{abstract}

\section{Introduction}

Maternal recognition of pregnancy is a long standing problem in reproductive biology. In the ewe (Moor \& Rowson, 1966) and cow (Betteridge, Eaglesome, Randall, Mitchell \& Sugden, 1978) the conceptus must be present in the uterus by Day 13 or 16 after mating for maintenance of the corpus luteum (CL) and continuation of pregnancy. Thus, in both species the signal emitted due to the presence of an embryo has been transmitted even before the extraembryonic tissue becomes attached to the uterine epithelium. The mechanism responsible for maintenance of a CL during early pregnancy and, in particular, the way in which the embryo influences this process are not clearly understood but may involve a local effect of the conceptus on uterine blood flow. Greiss \& Anderson (1970) observed transient increases in blood flow to the gravid uterine horn of ewes between Days 12 and 16 after mating. Effects of the ovine conceptus on uterine blood flow observed by Greiss \& Anderson (1970) occur during the same period when the presence of the embryo has been determined to be essential to ensure continued maintenance of the CL in the ipsilateral ovary (Moor \& Rowson, 1966).

This study was conducted in an effort to characterize the pattern of blood flow to uteri of cows during the oestrous cycle and early pregnancy and to provide insight into the effect of the early bovine conceptus on the uterine blood supply. The correlation of uterine blood flow with concentrations of oestradiol and progesterone in systemic blood was also studied. 


\section{Materials and Methods}

\section{Measurement of uterine blood flow}

Factory-calibrated blood-flow transducers $(8,10$ or $12 \mathrm{~mm}$ internal circumference) were chronically implanted around both middle uterine arteries of 7 multiparous Hereford cows, 5-7 years old. A square-wave electromagnetic flow meter (Model 501D, Carolina Medical Electronics, Inc., King, North Carolina) that received an electrical input from the flow transducer probes was used to measure uterine blood flow $(\mathrm{ml} / \mathrm{min})$.

The cows used in this study had at least 3 consecutive oestrous cycles of normal duration and were stanchioned daily from 08:00 to 17:00 h for 2 weeks before surgery. During this 2 week acclimatization period, any animal which did not readily adjust to handling and confinement was removed from the experiment. Vasectomized bulls were used to check oestrus twice daily $(07: 00$ and 17:00 h) throughout the experiment. Food and water were removed from the cows $24 \mathrm{~h}$ before surgery which was performed on Day 8, 9 or 10 of the oestrous cycle. General anaesthesia was induced by intravenous infusion of glyceryl guaiacolate (Gecolate: Summit Hill Labs, Avalon, New Jersey), sodium thiopental (Dipentol: Diamond Labs, Des Moines, Iowa) and dextrose which allowed introduction of a cuffed endotracheal tube. Surgical anaesthesia was maintained with mixtures of oxygen, nitrous oxide and halothane (Fluothane: Ayerst Labs, New York, N.Y.) administered in closed-circuit with soda lime for removal of $\mathrm{CO}_{2}$.

The uterus and ovaries were exposed through a midventral incision, and a segment of the middle uterine artery supplying each uterine horn was exposed immediately before its first bifurcation in the mesometrium. The adventitia was removed from a $1 \mathrm{~cm}$ segment, and the vessel diameter measured. A flow transducer head was passed through a small flank incision into the abdominal cavity, placed around the artery, and fixed within the broad ligament with a series of silk sutures. The electrical connector of each flow transducer, for attachment to the electromagnetic flow meter, was sutured to an elastic patch which was glued to the flank over the site of entry.

After surgery, cows were returned to the stanchioning routine. Beginning on the 2nd day after placement of the probes, blood flow $(\mathrm{ml} / \mathrm{min}$ ) through each uterine artery was monitored continuously for $30 \mathrm{~min}$. Blood flow values displayed by the flow meter at 15 -sec intervals during each daily 30 -min monitoring period were recorded. Recorded values were averaged over the 30 min period for each artery and considered an estimate of uterine arterial blood flow for that day. Preliminary observations using one cow demonstrated that blood flow to the uterus differed very little between 09:00 and 17:00 h on any given day during an oestrous cycle. Because of this observation and the time involved in monitoring, cows were randomly assigned for monitoring daily beginning at 09:00 or 14:00 h. During the sessions, the use of the right or left artery first was alternated each day.

At the first oestrus after placement of the probes, all cows were mated to an intact bull. Cows were palpated per rectum on Day 10 after mating to determine which ovary contained the CL. The uterine artery supplying blood to the uterine horn ipsilateral to the ovary bearing the CL will be referred to hereafter as the ipsilateral artery, whereas the uterine artery supplying blood to the uterine horn contralateral to the ovary bearing a CL will be referred to hereafter as the contralateral artery. Animals were slaughtered after their return to oestrus (non-pregnant) or, if no oestrous activity was exhibited, on Days 30-35 after mating (pregnant). Pregnancy and placement of flow transducers were verified at slaughter. One of the 7 cows used did not exhibit behavioural oestrus after placement of the probes and was removed from the experiment.

After removal at slaughter, the calibration factors of 3 blood flow transducers ( 1 of each size used in this study) were verified in vitro. The in-vitro calibration check was accomplished by perfusing heparinized cow blood through a segment of bovine uterine artery submerged in isotonic saline $(0.9 \%(\mathrm{w} / \mathrm{v}) \mathrm{NaCl})$. Blood was perfused through the vessel at known rates $(3.82-$ $76.4 \mathrm{ml} / \mathrm{min}$ ) with a Harvard dual syringe infusion pump, and blood flow, as indicated by the 
electromagnetic flow meter, was recorded. As illustrated in Text-fig. 1, the relationship between the perfused blood flow and that indicated by the electromagnetic flow meter display was linear $(P<0.05)$ over the range studied.

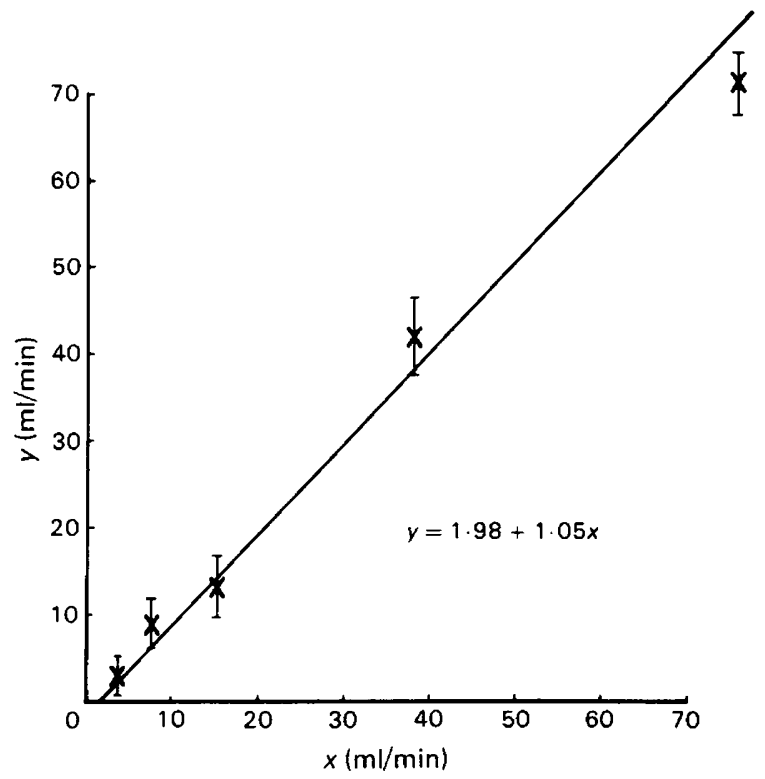

Text-fig. 1. Relationship between blood perfused at known rates through an arterial segment in vitro $(x)$ and blood flow as indicated by an electromagnetic flow meter display $(y)$. Each point represents the mean \pm s.e.m. of 3 determinations.

\section{Ovarian steroid measurements}

A jugular cannula, inserted at the time of surgery, was used to obtain blood from each cow after daily monitoring of uterine blood flow for determination of serum oestradiol-17 $\beta$ and progesterone. Radioimmunoassay of progesterone was a modification of a procedure described previously by Abraham, Hopper, Tulchinsky, Swerdloff \& Odell (1971) and utilized the same, fully characterized antiserum (S-49 No. 6). Although the same antiserum was used, blood serum was extracted with heptane instead of diethyl ether to improve recovery and chromatography was omitted. Sensitivity of the assay was defined as the amount of progesterone standard which yielded $95 \%$ of the counts $/ \mathrm{min}$ in the buffer control tubes; this amount ranged from 5 to $7.8 \mathrm{pg}$. With this method, the blank value for serum from a cow on the day of oestrus was $0.40 \pm 0.03$ $\mathrm{ng} / \mathrm{ml}$ (s.e.m., $n=4$ ). The precision and accuracy of the procedure was evaluated by adding $0.05(n=4), 0.13(n=4), 0.25(n=4), 0.50(n=4), 1.25(n=4), 2.50(n=4)$ and $5.00(n=$ 4) ng progesterone to this serum pool on a $\mathrm{ng} / \mathrm{ml}$ basis. These standard sera were assayed, and the progesterone concentration of the serum blank was subtracted. The resulting progesterone concentrations $( \pm$ s.e.m.) were $0.05 \pm 0.01,0.13 \pm 0.01,0.25 \pm 0.01,0.41 \pm 0.02,1.04 \pm$ $0.02,2.49 \pm 0.05$ and $4.88 \pm 0.05$, respectively. Within-assay variability was determined from replicates $(n=10)$ of a serum pool from luteal-phase cows. The resulting concentration ( \pm s.e.m.) was $1.94 \pm 0.02 \mathrm{ng} / \mathrm{ml}$ (coefficient of variation $=2.9 \%$ ). Between-assay variation determined by assaying duplicates of the above mentioned serum pool from luteal-phase cows in each assay $(n=8)$ was $5 \cdot 9 \%$.

Quantitation of oestradiol was a slight modification of a procedure previously reported by Echternkamp \& Hansel (1973) which utilized column chromatography to separate and purify

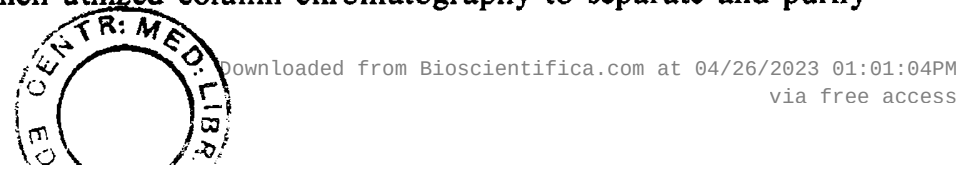


oestradiol-17 $\beta$ before radioimmunoassay. In contrast with the previous methodology, $2 \mathrm{ml}$ serum were extracted twice with 2.5 volumes of benzene and the final benzene extract was washed once with 1 volume of deionized water to remove any water-soluble contaminants prior to chromatography. The antiserum (S-1554 No. 6) was obtained commercially from Dr G. E. Abraham (Division of Reproductive Biology, Harbor General Hospital, 1000 West Carson Street, Torrance, California 90509). The antiserum was very specific for oestradiol-17 $\beta$, exhibiting little cross-reactivity with oestrone $(0.6 \%)$, oestriol $(<0.01 \%)$ or testosterone $(<0.01 \%)$. Sensitivity of the assay, defined as the amount of oestradiol- $17 \beta$ standard which yielded $95 \%$ of the counts $/ \mathrm{min}$ in the buffer control tubes, ranged from 1.8 to $2.3 \mathrm{pg}$. The precision and accuracy of this procedure was evaluated by adding $10,20,40,50$ and $80 \mathrm{pg}$ oestradiol- $17 \beta$ to charcoal-stripped plasma from an ovariectomized cow. These standard sera were assayed, and the oestradiol concentration of the serum blank was subtracted. The resulting oestradiol concentrations $( \pm$ s.e.m.) were $10.0 \pm 0.6(n=4), 20.7 \pm 1.6(n=4), 45.0 \pm 2.9$ $(n=4), 58.8 \pm 4.2(n=4)$ and $81.8 \pm 2.8(n=4)$, respectively. Within-assay variability, determined from duplicates, was $<20 \%$. Between-assay variation was determined by assaying duplicates of a pooled serum from oestrous cows and a pool of serum from cows during the luteal phase of the oestrous cycle in each assay $(n=6)$. Concentrations $( \pm$ s.e.m.) of oestradiol were $8.0 \pm 0.2 \mathrm{pg} / \mathrm{ml}$ for the pool of serum from oestrous cows and $4.3 \pm 0.3 \mathrm{pg} / \mathrm{ml}$ for the pool from luteal-phase cows.

\section{Statistical analyses}

Daily blood flow averages for each artery were considered as a single observation for statistical analyses to characterize time trends. Uterine arterial blood flow responses and changes in systemic concentrations of ovarian steroids were analysed by split-plot analysis of variance techniques (Kirk, 1968). Differences between means were tested for significance by using orthogonal contrasts. In addition, a series of least squares analyses was conducted to determine time changes in uterine arterial blood flow. The statistical model included conditions (pregnant or non-pregnant), artery within condition (ipsilateral or contralateral) and time, as a continuous independent variable, to the highest order of significance. The test for significance was a test of heterogeneity of regression (Snedecor \& Cochran, 1967). With this test, effects are significant when there is significant gain in fitting one curve for each component over fitting an overall pooled curve. Correlations between serum concentrations of progesterone, oestradiol and uterine blood flow were also investigated.

\section{Results}

Rates of uterine blood flow through the ipsilateral and contralateral uterine arteries did not differ significantly on any day during the oestrous cycle in the non-pregnant cows $(n=3)$ as determined by analysis of variance or heterogeneity of regression. Thus, ipsilateral and contralateral uterine arterial blood flow curves were pooled for the non-pregnant cows. Blood flow was different $(P<0.01)$ between the ipsilateral uterine artery and contralateral uterine artery of pregnant cows $(n=3)$ during the first 30 days of pregnancy as determined by similar tests.

\section{Non-pregnant cows}

Blood flow to uteri of the 3 non-pregnant cows followed a consistent cyclic pattern as illustrated in Text-fig. 2. Uterine blood flow was highest from 2 days before onset of oestrus to Day 1 of the oestrous cycle. By Day 2 a decrease in blood flow had occurred followed by a 


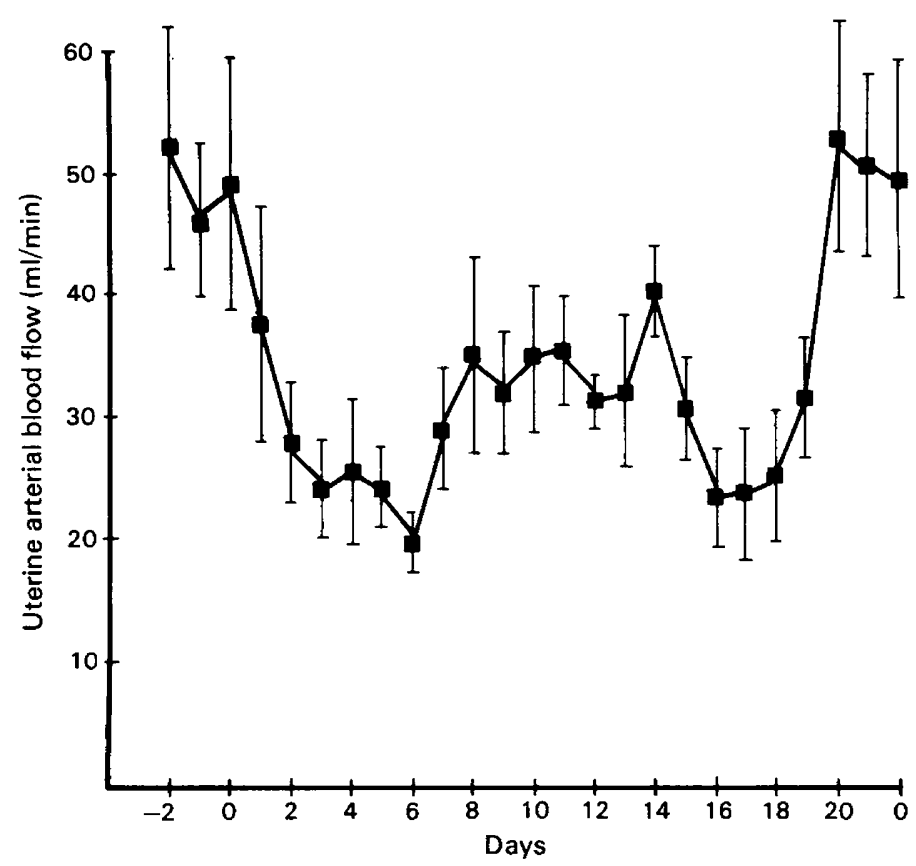

Text-fig. 2. Pattern of blood flow to uteri of 3 non-pregnant cows throughout the oestrous cycle (Day $0=$ oestrus). Each point represents the mean \pm s.e.m. of 6 uterine arteries $(3$ ipsilateral and 3 contralateral).

gradual decline to Day 6. All 3 non-pregnant cows exhibited 2 transient increases in uterine blood flow between Days 7 and 15 of the cycle, followed by a decline on Day 16 which preceded the rise in uterine blood flow 2 days before the subsequent oestrus.

Serum concentrations of progesterone and oestradiol throughout the oestrous cycle of the non-pregnant cows are illustrated in Text-fig. 3. Progesterone concentration in systemic blood began to increase $(P<0.05)$ on Day 5 of the cycle and attained a maximal concentration by

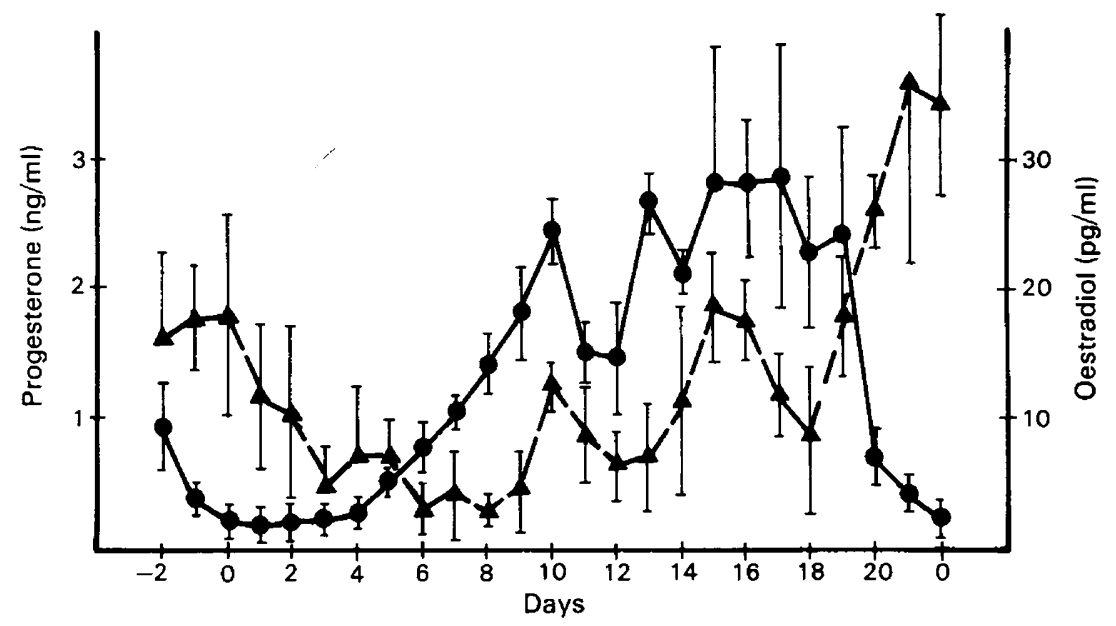

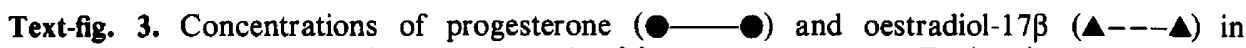
systemic blood throughout the oestrous cycle of 3-non-pregnant cows. Each point represents the mean \pm s.e.m. Day $0=$ oestrus. 
Day 10. From Days 10 through 19, progesterone concentration remained relatively constant before declining to a low level 2 days before the subsequent oestrus on Day 22 . Serum concentrations of oestradiol were highest at oestrus, and 2 transient increases were observed during the luteal phase of the oestrous cycle in all cows. Concentrations of oestradiol increased between Days 9 and 12 and between Days 13 and 18 of the oestrous cycle.

Uterine blood flow during the oestrous cycle was positively correlated $(r=0.36, P<0.01)$ with systemic concentrations of oestradiol and the ratio of oestradiol $(\mathrm{pg} / \mathrm{ml})$ to progesterone (ng/ml; $r=0.26, P<0.01$ ).

\section{Pregnant cows}

The pattern of blood flow to the uteri of pregnant cows was similar to that of non-pregnant cows until Day 13 after mating (Text-fig. 4). Between Days 14 and 18 of pregnancy, blood flow through the uterine artery supplying the gravid horn increased $(P<0.01) 2$ - to 3 -fold, whereas blood flow through the contralateral uterine artery remained constant. By Day 19 of pregnancy, blood flow through the ipsilateral uterine artery had returned to a flow rate similar to that observed on Day 13. Blood flow to both uterine horns of the pregnant cows remained constant from Day 19 until Day 25 when blood flow to the gravid horn increased $(P<0.01)$ markedly to Day 30. In contrast, blood flow through the contralateral uterine artery exhibited a progressive decline $(P<0.05)$ from Day 24 to Day 30.

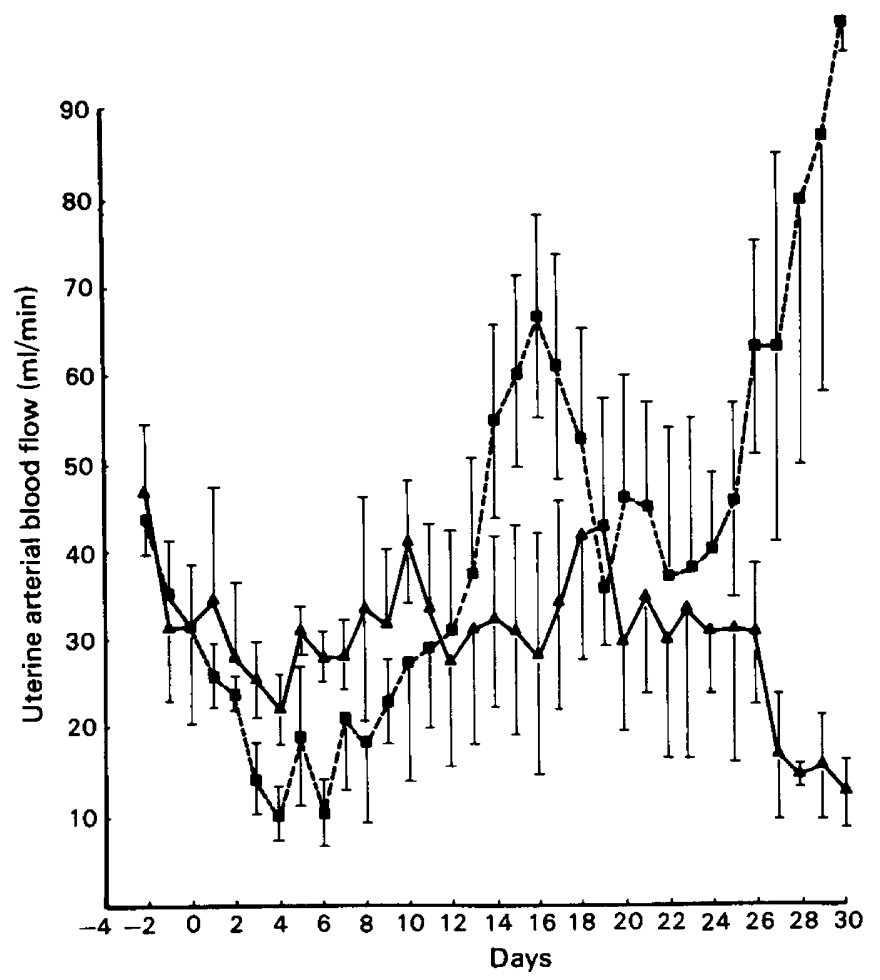

Text-fig. 4. Pattern of blood flow to both uterine horns of 3 cows throughout the first 30 days of pregnancy (Day $0=$ day of mating). Each point represents the mean \pm s.e.m. for 3 gravid uterine horns $(\mathbf{E}-\mathbf{E})$ and 3 non-gravid $(\mathbf{\Delta}-\mathbf{\Delta})$ horns. 
From 0 to 19 days of pregnancy, concentrations of progesterone in the systemic blood followed a pattern similar to that observed during the oestrous cycle of non-pregnant cows (Text-fig. 5). Instead of declining to a low level as observed in non-pregnant cows on Day 20, progesterone concentrations of pregnant cows remained high and relatively constant for the remainder of the 30-day monitoring period. As observed in the non-pregnant cows, oestradiol concentrations in the blood of pregnant cows were highest at oestrus followed by 2 transient peaks between Days 5 and 8 and between Days 14 and 17 of pregnancy. Concentrations of oestradiol remained relatively constant from Day 19 to Day 30 of pregnancy.

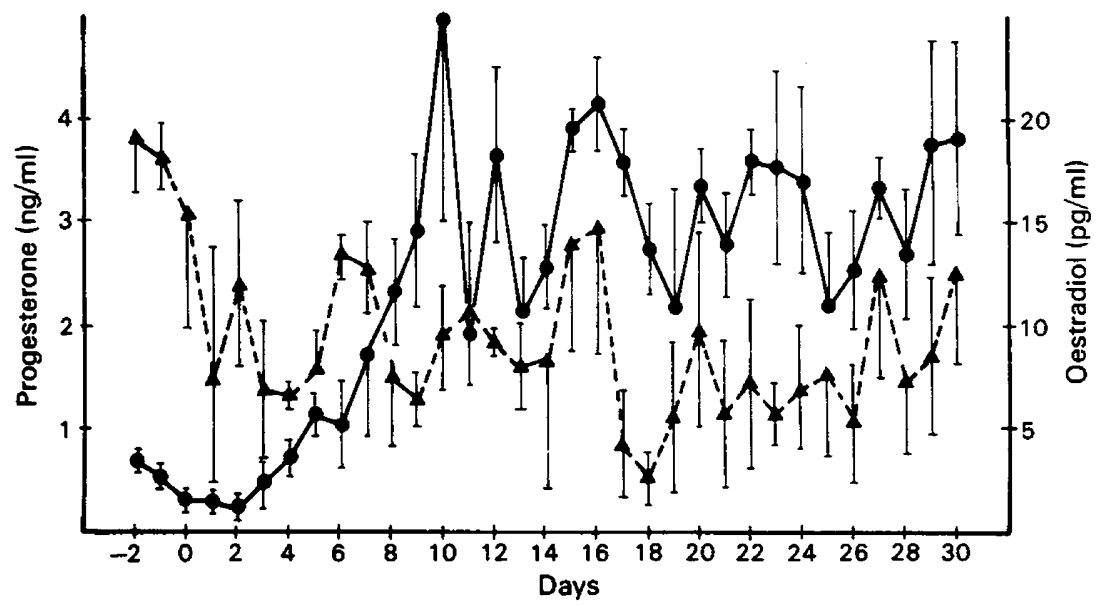

Text-fig. 5. Concentrations of progesterone (-) and oestradiol-17 $\beta(\Delta---\Delta)$ in systemic blood of 3 cows throughout the first 30 days of pregnancy (Day $0=$ day of mating). Each point represents the mean \pm s.e.m.

Unlike the non-pregnant cows, no association could be demonstrated between blood flow through the ipsilateral or contralateral uterine arteries of pregnant cows during the first 30 days of pregnancy and systemic concentrations of oestradiol or the ratio of oestradiol to progesterone. However, a positive correlation was observed between blood flow to the gravid uterine horn and systemic concentrations of progesterone $(r=0.44, P<0.01)$. No demonstrable association existed between blood flow through the contralateral uterine artery of these pregnant cows and blood progesterone.

\section{Discussion}

The results of this study clearly indicate local control of uterine blood flow by the early bovine conceptus. In cows (Betteridge et al., 1978) the conceptus must be present in the uterus by Day 16 after mating for maintenance of the $\mathrm{CL}$ and pregnancy. As in ewes (Greiss \& Anderson, 1970 ), blood flow to the gravid horn of cows increased on the days critical for ensuring prolongation of the life-span of the CL. Failure of the contralateral uterine artery to exhibit a corresponding increase in blood flow on Days 14 to 18 of pregnancy may reflect a unilateral signal initiated by the bovine conceptus and/or a differential sensitivity of the 2 uterine arteries for the signal.

In support of the latter premise, Ford, Weber \& Stormshak (1976) observed that uterine arteries ipsilateral to ovaries bearing CL from Day-17 non-pregnant heifers and Day-15 nonpregnant ewes responded to in-vitro nerve stimulation with greater increases in constriction than did contralateral arteries. Arteries ipsilateral or contralateral to ovaries with CL in Day-17 
pregnant heifers and Day-15 pregnant ewes, however, exhibited no differences in responsiveness to nerve stimulation, due primarily to decreased constriction of ipsilateral arteries. These data suggest a preferential effect of the conceptus for reducing constriction of the uterine artery supplying the gravid horn.

The greater in-vitro constriction of uterine arteries from the luteal side in non-pregnant ewes and cows observed by Ford et al. (1976) was suggested as being due to exposure of these arteries to greatly increased concentrations of progesterone in ovarian lymph (Morris \& Sass, 1966; Lindner, Sass \& Morris, 1964). As secretion of progesterone increases throughout the luteal phase of the ovine oestrous cycle, constriction of uterine arteries ipsilateral to ovaries containing a CL increases in a parallel fashion (Ford et al., 1977a). In addition, Ford et al. (1977a) demonstrated an overall significant correlation $(r=0.72)$ between vasoconstriction to nerve stimulation and concentrations of progesterone in systemic blood. Progesterone has been observed to enhance constriction of vascular smooth muscle by reducing the rate of norepinephrine degradation (Kalsner, 1969), leading to increased levels of neurotransmitter in periarterial sympathetic neurones.

In some respects the increased blood flow to the gravid horn caused by the presence of the preimplantation bovine conceptus mimics the effects of oestrogen. Oestrogen is known to exert a profound effect on uterine haemodynamics. Uterine hyperaemia following oestrogen administration has been demonstrated in the ewe (Huckabee, Crenshaw, Curet, Mann \& Barron, 1970) and cow (Roman-Ponce, Thatcher, Caton, Barron \& Wilcox, 1978). In addition, injection of oestrogen into the uterine lumen (Greiss \& Miller, 1971) or into the uterine artery (Resnik, Killam, Battaglia, Makowski \& Meschia, 1974) of the ewe causes a rapid unilateral increase in uterine blood flow. Administration of oestrogen to ovariectomized ewes also was found to reduce the constrictor responses of uterine arteries to nerve stimulation (Ford et al., 1977b). The data of Ford et al. (1977b) are supported by research conducted by McKercher, Van Orden, Bhatnagar \& Burke (1973) who observed that injection of oestradiol into ovariectomized rats reduced the norepinephrine content of uterine periarterial adrenergic nerves before increasing blood flow. It has been demonstrated previously that the Day-14 and -15 porcine conceptus can synthesize oestrogens in vitro (Perry, Heap \& Amoroso, 1973). In addition, Ward, Frost \& Ward Orsini (1978) suggest that oestrogen diffusing from implanting rat embryos partly saturate the hormone binding capacity of the adjacent endometrium. Oestrogens of embryonic origin may therefore act locally and directly to alter uterine arterial blood flow.

The consistent repetitive pattern of blood flow to uteri of non-pregnant cows during the oestrous cycle in this study was similar to that reported for the ewe by Greiss \& Anderson (1969) who suggested that the abrupt increase in uterine arterial blood flow observed at oestrus may have resulted from a vasodilatory action of oestradiol, whereas the gradual decline in blood flow after oestrus may have resulted from progesterone-induced vasoconstriction. Caton, Abrams, Clapp \& Barron (1974) demonstrated an antagonistic effect of oestrogen and progesterone on uterine arterial blood flow in the ovariectomized ewe: oestradiol-stimulated increases in blood flow through the uterine vascular bed were decreased by administration of progesterone and the magnitude of the induced changes appeared to be related to the ratio of the two steroids. These data agree well with the present study of cows in which uterine arterial blood flow throughout the oestrous cycle was found to be correlated $(P<0.01)$ with serum concentrations of oestradiol, as well as the ratio of oestradiol to progesterone.

In addition to the relatively large increases in uterine arterial blood flow observed at oestrus, 2 transient increases in blood flow of reduced magnitude were observed during the luteal phase of the oestrous cycle in each cow. These increases were associated with increased concentrations of oestradiol in systemic blood, possibly of follicular origin since Mattner \& Braden (1972) demonstrated that ovaries of the ewe secreted relatively large amounts of oestradiol-17 $\beta$ during 3 separate periods during the luteal phase of the oestrous cycle in association with waves of follicular development. 
Holness, Ellison \& Wilkins (1977) reported that systemic concentrations of progesterone were higher in pregnant cows than in non-pregnant cows as early as Day 13 after insemination. Similar differences in blood progesterone concentrations between pregnant and non-pregnant cows have been reported by others (Henricks, Dickey \& Niswender, 1970; Henricks, Lamond, Hill \& Dickey, 1971); and Henricks et al. (1971) have suggested that the conceptus acts by direct or indirect stimulation of the $\mathrm{CL}$ or by causing a change in the degradation of progesterone. Increased blood concentrations of progesterone during early pregnancy may be important to survival of embryos. Recent observations by Anderson, Hackshaw, Still and Greiss (1977) indicate that progesterone administration to ovariectomized ewes results in a redistribution of uterine blood flow in favour of the caruncles, the sites of embryo attachment.

Of interest in the present investigation is the observation that an overall significant correlation exists between uterine arterial blood flow to the uterine horn containing the conceptus and systemic concentrations of progesterone. In addition, the concentration of progesterone in systemic blood of pregnant cows was higher $(P<0.05)$ than that of non-pregnant cows from Days 14 to 18 after mating $(3.27 \pm 0.28$ versus $2.36 \pm 0.26)$. It has been demonstrated that levels of progesterone in blood are a reliable measure of luteal function (Stormshak, Inskeep, Lynn, Pope \& Casida, 1963) and are correlated with blood flow through the CL of the ewe (Niswender, Reimers, Diekman \& Nett, 1976) during the oestrous cycle. Thus the conceptusinduced increases in blood flow to the gravid horn of cows in this study may be accompanied by increased blood flow through the CL resulting in increased secretion of progesterone. During natural (Niswender et al., 1976) as well as prostaglandin F-2 $\alpha$-induced (Nett, McClellan \& Niswender, 1976) luteal regression, blood flow to the ovary with CL declines sharply with a reduced secretion of progesterone. It is possible that the conceptus produces or stimulates uterine synthesis of a factor which dilates the ipsilateral utero-ovarian vasculature, thus creating optimal conditions for the continuation of pregnancy.

The progressive rise in blood flow to the uterine horn containing the conceptus beginning on Day 25 may be associated with implantation. Attachment of the bovine conceptus to the uterine wall is a gradual process with the first points of attachment occurring immediately around the embryo by Day 30 (Melton, Berry \& Butler, 1951). Unlike the ewe, in which increases in blood flow to both the gravid and non-gravid uterine horns of unilaterally pregnant animals were associated with the initiation of implantation (Greiss and Anderson, 1970), blood flow to the non-gravid uterine horn of cows in this study remained low.

Appreciation is expressed to Bill McDonald for his technical assistance and to Dave Mitchell and Gary Peterson for the care of experimental animals, and help with the daily monitoring of uterine arterial blood flow. Co-operation of the Agricultural Experiment Station, University of Nebraska is acknowledged.

Mention of a trade name, proprietary product, or specific equipment does not constitute a guarantee or warranty by the U.S. Department of Agriculture and does not imply its approval to the exclusion of other products that may be suitable.

\section{References}

Abraham, G.E., Hopper, K., Tulchinsky, D., Swerdloff, R.S. \& Odell, W.D. (1971) Simultaneous measurement of plasma progesterone, 17-hydroxyprogesterone and oestradiol- $17 \beta$ by radioimmunoassay. Analytical Letters 4, 325-335.

Anderson, S.G., Hackshaw, B.T., Still, J.G. \& Greiss, F.C., Jr (1977) Uterine blood flow and its distribution after chronic estrogen and progesterone administration. Am. J. Obstet. Gynec. 127, 138-142.
Betteridge, K.J., Eaglesome, M.D., Randall, G.C.B., Mitchell, D. \& Sugden, E.A. (1978) Maternal progesterone levels as evidence of luteotrophic or antiluteolytic effects of embrvos transferred to heifers 12-17 days after estrus. Theriogenology 9, 86, Abstr.

Caton, D., Abrams, R.M., Clapp, J.F. \& Barron, D.H. (1974) The effect of exogenous progesterone on the rate of blood flow of the uterus of ovariectomized sheep. Q. Jl exp. Physiol. 59, 225-231. 
Echternkamp, S.E. \& Hansel, W. (1973) Concurrent changes in bovine plasma hormone levels prior to and during the first postpartum estrous cycle. $J$. Anim. Sci. 37, 1362-1370.

Ford, S.P., Weber, LJ. \& Stormshak, F. (1976) In vitro response of ovine and bovine uterine arteries to prostaglandin $\mathrm{F}_{2} \alpha$ and periarterial sympathetic nerve stimulation. Biol. Reprod. 15, 58-65.

Ford, S.P., Weber, L.J. \& Stormshak, F. (1977a) Response of ovine uterine arteries to nerve stimulation after perfusions of prostaglandin $F_{2} \alpha$, norepinephrine or neurotransmitter antagonists. Endocrinology 101, 659-665.

Ford, S.P., Weber, L.J. \& Stormshak, F. (1977b) Role of estradiol-17 $\beta$ and progesterone in regulating constriction of ovine uterine arteries. Biol. Reprod. $17,480-483$.

Greiss, F.C., Jr \& Anderson, S.G. (1969) Uterine vascular changes during the ovarian cycle. $A \mathrm{~m}$. J. Obstet. Gynec. 103, 629-640.

Greiss, F.C., Jr \& Anderson, S.G. (1970) Uterine blood flow during early ovine pregnancy. Am. J. Obstet. Gynec. 106, 30-38.

Greiss, F.C., Jr \& Miller, H.B. (1971) Unilateral control of uterine blood flow in the ewe. Am. J. Obstet. Gynec. 111, 299-301.

Henricks, D.M., Dickey, J.F. \& Niswender, G.D. (1970) Serum luteinizing hormone and plasma progesterone levels during the oestrous cycle and early pregnancy in cows. Biol. Reprod. 2, 346-351.

Henricks, D.M., Lamond, D.R., Hill, J.R. \& Dickey, J.F. (1971) Plasma progesterone concentrations before mating and in early pregnancy in the beef heifer. $J$. Anim. Sci. 33, 450-454.

Holness, D.H., Ellison, J.A. \& Wilkins, L.M. (1977) Conception of beef cows in relation to the concentration of progesterone in peripheral blood. Rhod. J. agric. Res. 15, 3-9.

Huckabee, W.E., Crenshaw, C., Curet, L.B., Mann, L. \& Barron, D.H. (1970) The effect of exogenous oestrogen on the blood flow and oxygen consumption of the uterus of the nonpregnant ewe. $Q$. Jl exp. Physiol. 55, 16-24.

Kalsner, S. (1969) Steroid potentiation of responses to sympathomimetic amines in aortic strips. Br. $J$. Pharmac. 36, 582-593.

Kirk, R.E. (1968) Experimental Design-Procedures for the Behavioral Sciences. Wadsworth Publishing Co., Belmont, California.
Lindner, H.R., Sass, M.B. \& Morris, B. (1964) Steroids in the ovarian lymph and blood of conscious ewes. $J$. Endocr. 30, 361-376.

Mattner, P.E. \& Braden, A.W.H. (1972) Secretion of oestradiol $-17 \beta$ by the ovary during the luteal phase of the oestrous cycle in relation to ovulation. $J$. Reprod. Fert. 28, 136-137, Abstr.

McKercher, T.C., Van Orden, L.S., III, Bhatnagar, R.K. \& Burke, J.P. (1973) Estrogen-induced biogenic amine reduction in rat uterus. J. Pharmac. exp. Ther. 185, 514-522.

Melton, A.A., Berry, R.O. \& Butler, O.D. (1951) The interval between the time of ovulation and attachment of the bovine embryo. J. Anim. Sci. 10, 9931005.

Moor, R.M. \& Rowson, L.E.A. (1966) Local maintenance of the corpus luteum in sheep with embryos transferred to various isolated portions of the uterus. J. Reprod. Fert. 12, 539-550.

Morris, B. \& Sass, M.B. (1966) The formation of lymph in the ovary. Proc. R. Soc. B 164, 577-591.

Nett, T.M., McCellan, M.C. \& Niswender, G.D. (1976) Effects of prostaglandins on the ovine corpus luteum: blood flow, secretion of progesterone and morphology. Biol. Reprod. 15, 66-78.

Niswender, G.D., Reimers, T.J., Diekman, M.A. \& Nett, T.M. (1976) Blood flow: a mediator of ovarian function. Biol. Reprod. 14, 64-81.

Perry, J.S., Heap, R.B. \& Amoroso, E.C. (1973) Steroid hormone production by pig blastocysts. Nature, Lond. 245, 45-47.

Resnik, R., Killam, A.P., Battaglia, F.C., Makowski, E.L. \& Meschia, G. (1974) The stimulation of uterine blood flow by various estrogens. Endocrinology 94, 1192-1196.

Roman-Ponce, H., Thatcher, W.W., Caton, D., Barron, D.H. \& Wilcox, C.J. (1978) Thermal stress effects on uterine blood flow in dairy cows. J. Anim. Sci. 46, 175-180.

Snedecor, G.W. \& Cochran, W.G. (1967) Statistical Methods. The Iowa State University Press, Ames.

Stormshak, F., Inskeep, E.K., Lynn, J.E., Pope, A.L. \& Casida, L.E. (1963) Progesterone levels in corpora lutea and ovarian effluent blood of the ewe. J. Anim. Sci. 22, 1021-1026.

Ward, W.F., Frost, A.G. \& Ward Orsini, M. (1978) Estrogen binding by embryonic and interembryonic segments of the rat uterus prior to implantation. Biol. Reprod. 18, 598-601. 